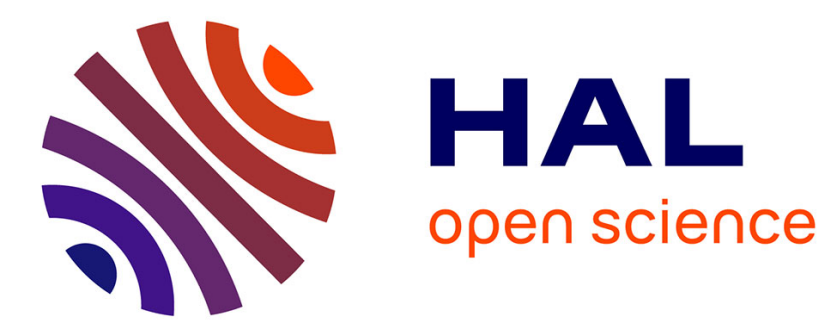

\title{
Antecedents and Consequences of Group-Based Guilt: The Effects of Ingroup Identification
}

\author{
Bertjan E. J. Doosje, Nyla R. Branscombe, Russell Spears, Antony S. R. \\ Manstead
}

\section{> To cite this version:}

Bertjan E. J. Doosje, Nyla R. Branscombe, Russell Spears, Antony S. R. Manstead. Antecedents and Consequences of Group-Based Guilt: The Effects of Ingroup Identification. Group Processes and Intergroup Relations, 2006, 9 (3), pp.325-338. 10.1177/1368430206064637 . hal-00571621

\section{HAL Id: hal-00571621 \\ https://hal.science/hal-00571621}

Submitted on 1 Mar 2011

HAL is a multi-disciplinary open access archive for the deposit and dissemination of scientific research documents, whether they are published or not. The documents may come from teaching and research institutions in France or abroad, or from public or private research centers.
L'archive ouverte pluridisciplinaire HAL, est destinée au dépôt et à la diffusion de documents scientifiques de niveau recherche, publiés ou non, émanant des établissements d'enseignement et de recherche français ou étrangers, des laboratoires publics ou privés. 


\title{
Antecedents and Consequences of Group-Based Guilt: The Effects of Ingroup Identification
}

\author{
Bertjan E. J. Doosje \\ University of Amsterdam
}

Nyla R. Branscombe

University of Kansas

\section{Russell Spears \\ Cardiff University \& University of Amsterdam}

\section{Antony S. R. Manstead}

Cardiff University

\begin{abstract}
Effects of ingroup identification on antecedents and consequences of group-based guilt were examined in two experiments. In the first study, ingroup identification was unrelated to guilt when the negative historical information was said to come from an outgroup source, but was positively related when the same information was said to come from an ingroup source. Among high identifiers it is difficult to dismiss negative information when the source is one's own ingroup. In the second study, people who are low in identification were more in favor of acknowledging the negative aspects of their group's history as a way of alleviating feelings of guilt. We discuss the implications of these results for coming to terms with the legacy of a negative ingroup past.
\end{abstract}

KEYWORDS collective guilt, group-based emotion, ingroup identification, reparation

Apologizing for the wrongs of one's group seems to be in vogue. For example, in an important Vatican statement the Pope expressed his guilt (toward God) for the treatment of the Jews by Catholics over the last 2 millennia. While visiting South Africa, President

\section{Author's note}

Address correspondence to Bertjan Doosje, Department of Social Psychology, University of Amsterdam, Roetersstraat 15, 1018 WB, Amsterdam, The Netherlands [email: doosje@uva.nl] 
Clinton apologized to Nelson Mandela for slavery on behalf of White Americans. In South Africa, the 'truth-and-reconciliation' commission has encouraged White South Africans to confess their past immoral actions and express their guilt, in the hope that this will lead to improved relations between Black and White South Africans (Minow, 1998). Indeed, the dramatic increase during the last few years in the number of public expressions of national guilt or apologies around the world, has led Barkan (2000) to argue that 'Moral issues came to dominate public attention and political issues and displayed the willingness of nations to embrace their own guilt. This national selfreflexity is the new guilt of nations' (p. XVII). However, in most nations, the idea of expressing guilt or apologies for the past remains a highly sensitive and controversial issue. For example, despite repeated calls for the Australian Prime Minister to apologize to Aborigines on behalf of the government, there has been considerable reluctance by him to do so (Augoustinos \& LeCouteur, 2004). Similarly, in The Netherlands the national government debates their past involvement in slavery in Surinam and the colonization of Indonesia.

In two studies we investigate the issue of group-based guilt over the past (mis) treatment of a group by one's ancestors, and how this is related to the issue of apology. Specifically, we examine the implications of ingroup identification for feelings of group-based guilt as a result of one's ancestors having colonized another country. We argue when people feel a strong attachment to their group, they are motivated to search for and use methods of avoiding feelings of guilt about their group's past behavior. We expected that ingroup identification would play an important role both in terms of interacting with antecedents and consequences of group-based guilt. In Study 1, we investigate how the antecedent source of the historical information (ingroup or outgroup) interacts with group identification to affect the acceptance of group-based guilt. Study 2 examines the interactive role of the consequences of group-based guilt in terms of past reparation to the harmed group (apologies or financial restitution) and ingroup identification.

Social identity theory (Tajfel \& Turner, 1986) and self-categorization theory (Turner, Hogg, Oakes, Reicher, \& Wetherell, 1987) offer insight into when and why people's emotions will be influenced by the group to which they belong (Mackie, Devos, \& Smith, 2000). It is argued that people can experience feelings of guilt on behalf of their group when the behavior of other ingroup members is inconsistent with the present norms or values of the group. Groupbased guilt can be conceptualized as guilt that is experienced as a consequence of belonging to a group that has done something that is perceived as illegitimate (e.g. Branscombe, Doosje, \& McGarty, 2002). For example, Branscombe (1998) has shown that reminding people of the advantages they have had as a group in relation to another group (in this case men in relation to women) can lead to lowered collective selfesteem, potentially because feelings of guilt were induced based on that group membership. Other research has shown that people can feel guilty, as a Dutch person whose group has harmed Indonesia, a former Dutch colony (Doosje, Branscombe, Spears, \& Manstead, 1998), as a White American toward Black Americans because of slavery (Swim \& Miller, 1999), and as an employed person toward the unemployed (Montada \& Schneider, 1989).

Not everyone, however, is equally likely to experience feelings of guilt when faced with negative information about their group's past. Based on social identity theory (Tajfel \& Turner, 1986), we argue that people are motivated to hold a positive view of their group and they are more likely to do so to the extent that they identify with that group (Branscombe \& Wann, 1991, 1994; Doosje, Ellemers, \& Spears, 1995). If members attach great importance to a particular group membership, they are less likely to accept negative aspects of that group when confronted with information that portrays their group negatively (Branscombe, Ellemers, Spears, \& Doosje, 1999). We therefore argue that high identification may lead people to search for means of avoiding feelings of guilt (Doosje \& Branscombe, 2003). 
Research by Doosje et al. (1998, Study 2) supported this hypothesis. In that study Dutch participants were confronted with a short summary of the Dutch colonization of Indonesia, where the evaluative nature of the historical message was manipulated. One-third of the participants read a thoroughly negative history message, another third read a version in which a completely positive perspective on the colonization was presented, and a final third read a mixedvalence version. The level of identification with being Dutch was measured before this message was presented. The strongest feelings of groupbased guilt were experienced when the thoroughly negative history description was presented, and the weakest feelings of guilt occurred with the positive history. This was the case for both low and high identifiers. However, when the presented information was of mixedvalence, low identifiers reported higher levels of guilt than did high identifiers. It was argued that the greater guilt among the low identifiers compared to high identifiers was due to their differential willingness to accept negative aspects of their group membership. Only when the presented information was of mixedvalence is there sufficient scope to express such differential guilt reactions; in the other conditions, the messages were either unambiguously negative or positive, leaving less room for interpretation (e.g. Doosje, Spears, \& Koomen, 1995; Kunda, 1990; Stangor \& Ford, 1992).

In the present studies we aim to further test the notion that identification plays a crucial role in the experience of group-based guilt. Our basic assumption is that people who are highly identified with a group try to avoid feelings of guilt associated with their group when this is possible. In two studies we manipulate the possibilities for highly identified people to avoid feelings of guilt about their group's past behavior. In Study 1, we investigate this issue by exploring the interactive role of identification and a crucial antecedent of group-based guilt, namely the source of the negative information about one's group (ingroup or outgroup). It is argued that it is easier for highly identified people to dismiss negative information about one's group when they are told that the information is coming from an outgroup source rather than from an ingroup source. In Study 2, we examine the influence of identification and an important consequence of guilt in terms of past reparations by the ingroup (apologies or financial reparation) on present-day feelings of groupbased guilt. It is argued that it is easier for highly identified group members to avoid feelings of guilt when one's group has dealt with the past negative behavior in terms of financial reparation rather than apologies, because apologies constitute an explicit acknowledgment of the wrongs of the ingroup.

\section{Study 1}

In this study, we aim to investigate the role of ingroup identification in interaction with an important antecedent of group-based guilt, namely source of information. Previous research has shown the significance of identification in interaction with another type of antecedent - the degree of unfavorableness of information about the ingroup (Doosje et al., 1998). When it is possible for high identifiers to avoid feelings of guilt, we suggest that high identifiers will be motivated to do so depending on the source of that information. We expect to replicate the findings of Doosje et al. (1998), with low and high identifiers reporting about an equal level of group-based guilt when the source is an outgroup (e.g. historians from the USA) and the information is thoroughly negative. We expect highly identified people to question the credibility of the outgroup source. However, we expect a different pattern when the source of information is the ingroup (i.e. Dutch historians). On the basis of selfcategorization theory (Turner et al., 1987), we argue that the extent to which people perceive the source of negative information as accepted by the ingroup is likely to have an impact on feelings of group-based guilt, especially when the individual feels strong attachment to the ingroup. Specifically, it is expected that high identifiers will be more likely to experience group-based guilt than low identifiers when the source of information is the ingroup, because it 
is more difficult to dismiss information coming from their own group.

Previous research in the attitude domain is in line with the general idea that information becomes more self-relevant when there is overlap in terms of group membership between the source and the self. For example, it has been demonstrated that group members are more likely to pay attention to, and change their attitudes, when the source of information is an ingroup rather than an outgroup (e.g. Mackie, Gastardo-Conaco, \& Skelly, 1992; Mackie, Worth, \& Asuncion, 1990; Wetherell, 1987). In addition, people are more accepting of criticism of their ingroup when this comes from an ingroup member rather than from an outgroup member (Hornsey, Oppes, \& Svensson, 2002). In our view, messages from an ingroup source are particularly relevant for people who identify strongly with their group. We therefore expect people who are highly identified with their group will experience more group-based guilt than people low in ingroup identification when the negative information comes from an ingroup source.

In terms of behavior, guilt is predictive of reparations aimed at undoing the harm done, for example by offering financial restitution (e.g. Minow, 1998). Doosje et al. (1998) found that when people are presented with mixed valence information about their group's past, high identifiers were less likely to favor financial restitution to the harmed group than low identifiers. We expected to find this pattern again, particularly when the information comes from an outgroup source, because high identifiers may find a way to question the credibility of this source. We expected a less pronounced negative (or even positive) relation between identification and financial reparation when the source of information is an ingroup.

With respect to perceived credibility of the source of information, we expect to find similar patterns as for group-based guilt. From a selfcategorization perspective, it might be argued that people may perceive negative information about their group as more credible when the source is an ingroup rather than an outgroup. As the attitude literature has revealed, people are more likely to change their attitudes when the source of information is an ingroup. For example, Lorge (1936) found that people in the USA agreed more with statements when it was said that they were made by an ingroup member (Lincoln), than by an outgroup member (Lenin). We expect this tendency to be stronger when people identify strongly with their ingroup.

\section{Method \\ Participants Altogether, 233 undergraduates at a large Dutch university participated in this study during a large testing session. About $66 \%$ of these students were female. Their mean age was 21 years. Students received course credit for their participation, and were fully debriefed.}

Overview and design All participants received a 'Questionnaire about The Netherlands', starting off with an ingroup identification scale. Subsequently, the source of the historical information was manipulated by presenting participants with a message about the role of The Netherlands during the colonization of Indonesia that was supposedly written by historians from a particular country. Participants were led to believe that the text was written by either an ingroup or an outgroup source. Finally, participants reported the extent to which they felt group-based guilt, favored financial compensation to the harmed group, evaluated the credibility of the source of information, and completed manipulation checks.

Procedure Participants' national identity was made salient by having them complete an eightitem scale assessing level of ingroup identification with the Dutch. This measure was used by Doosje et al. (1998) and formed a reliable scale in the present study (Cronbach's alpha = .92). Examples of the items used are 'I identify with other Dutch people', 'Dutch people are an important group to me', and 'I feel attached to Dutch people'.

Manipulation of source of information Participants received a one-page summary of the 350 years during which the Dutch colonized 
Indonesia. This information was said to be written by historians, and depending on the condition, participants were told that those historians were from the ingroup (the Netherlands) or an outgroup (the USA). This historical description contained negative information about the Dutch during the colonization of Indonesia, including that the Dutch had exhausted the natural resources of Indonesia and that they had exploited the cheap labor force of Indonesia; it also contained two photos to increase the vividness of the information.

Dependent measures As a check on the source manipulation, participants were asked to indicate the country of the historians who wrote the summary. They could choose between 1 (The Netherlands), 2 (Indonesia), 3 (USA) and 4 (it did not say). As a check on the overall negative tone of the message, participants were asked to indicate how the Dutch had behaved in Indonesia during the colonization, according to the information just presented, on a scale ranging from 1 (extremely negative) to 7 (extremely positive).

The degree to which group-based guilt was accepted by participants was assessed by administering a three-item measure ('I feel guilty about the negative things the Dutch have done to Indonesians', 'I feel regret for the harmful past actions of the Dutch toward the Indonesians', and 'I can easily feel guilty about the bad outcomes received by Indonesians which were brought about by the Dutch in the past'), answered on scales ranging from 1 (strongly disagree) to 7 (strongly agree). These three items were used by Doosje et al. (1998) and formed a reliable scale in the current sample $($ alpha $=.84)$.

Financial compensation was measured using one item ('I think the Dutch government should make more money available to Indonesia because of the things we have done there in the past'), answered on a scale ranging from 1 (strongly disagree) to 7 (strongly agree). Perceived credibility of the source of information was assessed using five items that assessed credibility of the source (e.g. 'To what extent do you think these historians are reliable as the source of information?', 'To what extent do you think this source is honest?', all answered on scales ranging from 1 (not at all) to 7 (very much) $($ alpha $=.91)$.

\section{Results}

Manipulation and other checks Ninety-four percent of the participants indicated the correct nationality of the historians who wrote the information about the Dutch in Indonesia. Preliminary analyses revealed no differences with or without the $7 \%$ who answered incorrectly, so we decided to retain all participants for the main analyses. On another check, participants indicated that the information was negative for their ingroup $(M=1.52, S D=$ $0.93)$, deviating significantly from the scale midpoint $4(t(212)=39.87, p<.001)$.

Group-based guilt We predicted that ingroup identification would be unrelated to groupbased guilt when the historians were believed to come from the USA, but that identification would be positively related to guilt when Dutch historians were described as the source. A General Linear Model (GLM) procedure was performed on the measure of group-based guilt, using the source of information as a dichotomous independent variable and the level of identification as a continuous independent variable. No main effects emerged for the source $(F(1,229)=0.00, p=0.97)$, or the degree of identification $(F(1,229)=0.70, p=$ $.40)$, but the interaction between identification and source was significant $(F(1,229)=6.34, p<$ $.02)$. The pattern is displayed in Figure 1. Analyses of the betas indicate that in the USA condition there was no significant relation between identification and guilt $(\beta=-.11, t(1$, $112)=1.14, p=.24)$. The pattern in the Dutch condition is as expected: high identification was positively related to feelings of group-based guilt $(\beta=.21, t(1,117)=2.40, p<.02)$.

Financial compensation A GLM analysis on the financial compensation measure revealed a main effect of ingroup identification only ( $\beta=$ $-.16, F(1,229)=5.88, p<.02)$. As expected this relationship was negative: high identification tends to co-occur with low levels of being in 


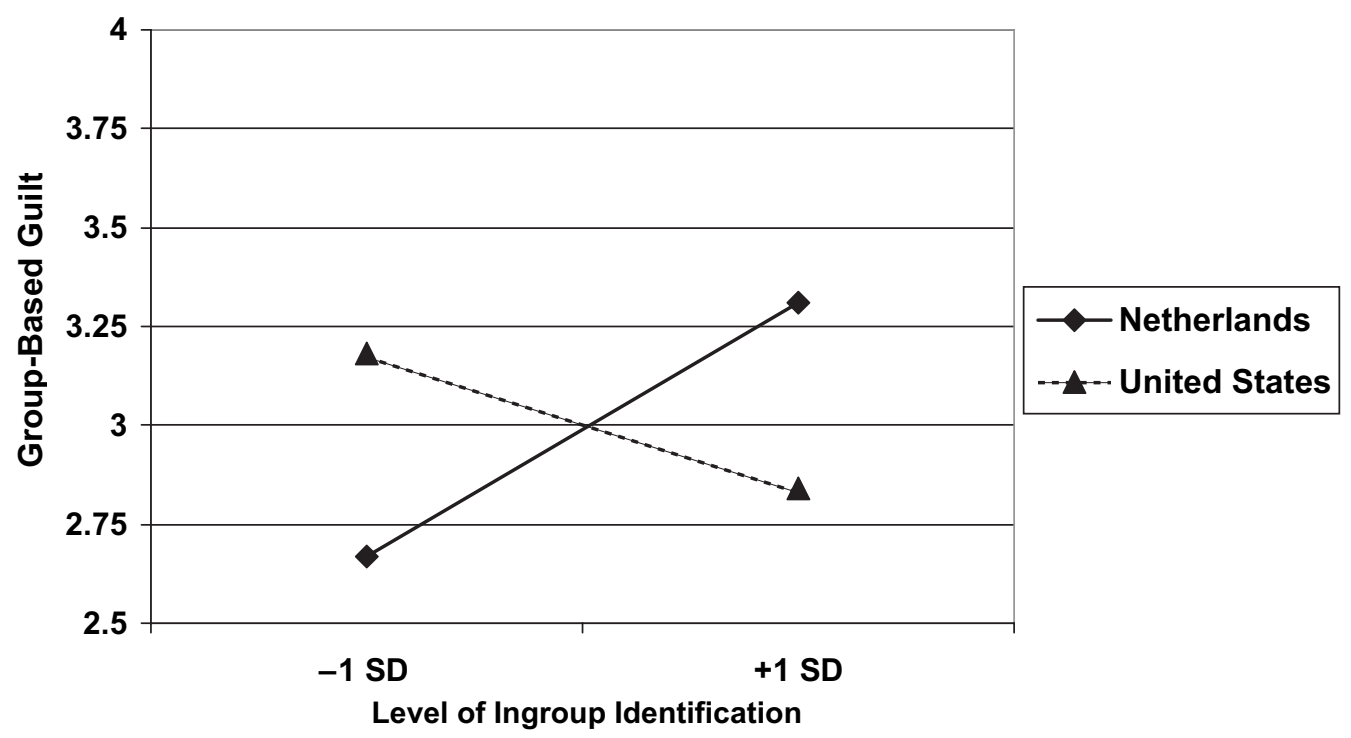

Figure 1. Group-based guilt as a function of source of information (Netherlands, Indonesia and United States) and ingroup identification ( $-1 \mathrm{SD},+1 \mathrm{SD})$ (Study 1).

favor of financial compensation by one's government. This main effect was not qualified by a significant interaction $(F(1,229)=0.00, p=.96)$.

Perceived credibility of the source A GLM analysis on the measure of perceived credibility of the source revealed no significant main effects of identification $(F(1,228)=2.57, p=$ $.11)$, but the main effect of source was reliable $(F(1,228)=21.66, p<.001)$. The Dutch source $(M=4.71)$ was perceived as more credible than the USA source $(M=3.96)$. As expected, this main effect was qualified by a significant interaction between identification and source $(F(1$, $228)=4.88, p<.03)$. The patterns are shown in Figure 2. As predicted, in the USA condition, identification was negatively related to perceived source credibility $(\beta=-.24, t(1,112)=$ $2.58, p<.02)$. Unexpectedly, identification was not related to perceived ingroup source credibility $(\beta=.05, t(1,117)=0.46, p=.65)$. Importantly, the significant interaction between identification and source indicates that the beta in the Dutch condition differs from the beta in the USA condition.

\section{Discussion}

In this study we examined the emotional reactions of people who differ in their level of identification with their group to a message that contains negative information about their ingroup's history as a function of an important antecedent of group-based guilt, namely the source of the negative information in terms of group membership. We observed that people who identify strongly with their group experience as much guilt as less identified group members when the source was an outgroup (historians from the USA) and the information was thoroughly negative. This replicates the findings obtained by Doosje et al. (1998, Study 2).

The present study goes beyond the prior research, however, by indicating that people perceived the USA source as least credible, and this pattern was stronger when ingroup identification increased. Thus, when exposed to groupthreatening information coming from an outgroup, group members (particularly those who identify strongly with their group) may question the credibility of the outgroup source. However, when the ingroup was the source of 


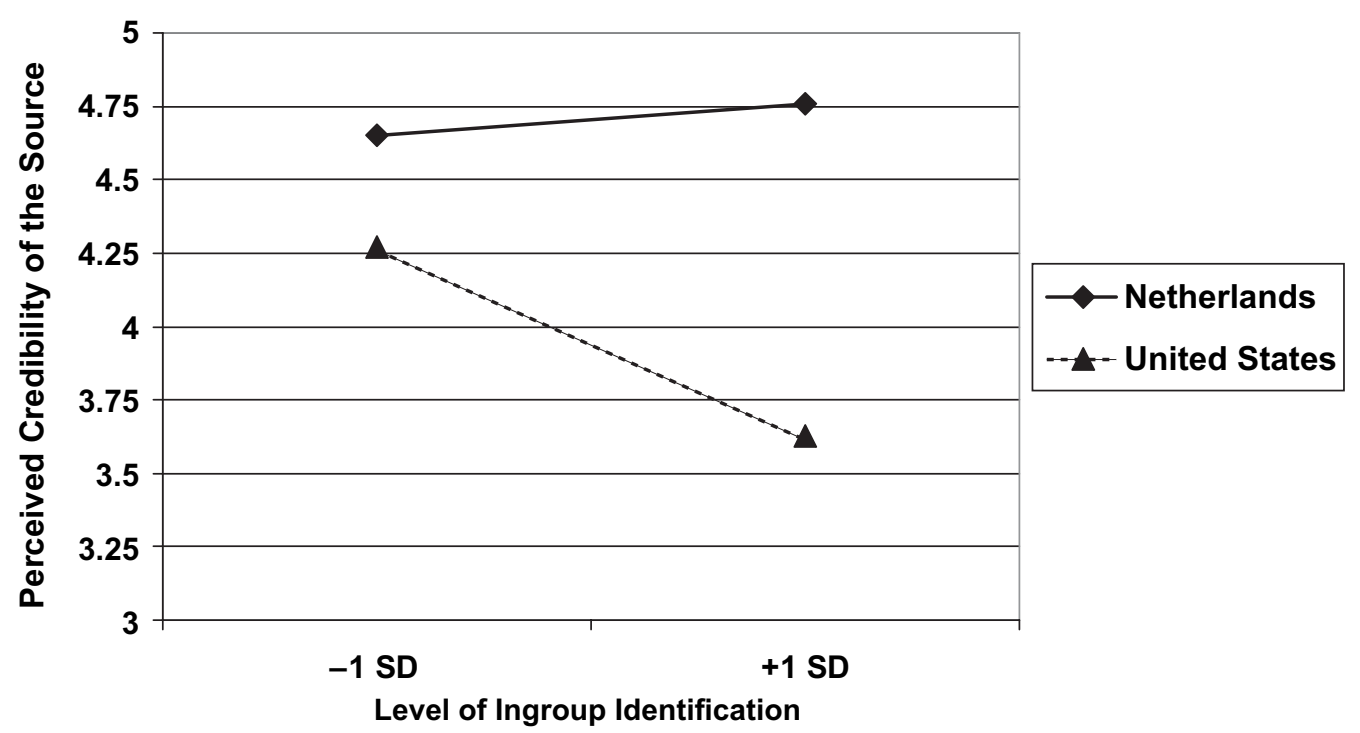

Figure 2. Perceived source credibility as a function of source of information (Netherlands, Indonesia and United States) and ingroup identification (-1 SD, +1 SD) (Study 1).

information, a different pattern was obtained: identification was positively related to groupbased guilt. Based on self-categorization theory, it was predicted that the extent to which people categorize the source as similar to the self in terms of group membership, the more persuasive the message should be (e.g. Turner et al., 1987). The effects on group-based guilt support this notion. However, even though the ingroup source was perceived as the most credible in this study, ingroup identification did not seem to influence the perception of source credibility. Thus, it is difficult to explain the effect of identification on group-based guilt when receiving a message from an ingroup member in terms of difference in perceived source credibility. Why, then, do low identifiers experience less group-based guilt than high identifiers when confronted with unfavorable information about their ingroup from an ingroup source? We address this question directly in our next study.

\section{Study 2}

In Study 2 we are interested in explaining the positive relation between ingroup identification and group-based guilt in response to an unfavorable message stemming from the ingroup. To do so, we focus on the effect of ingroup identification on an important consequence of group-based guilt, namely reparation to the harmed group. Such reparations may take different forms, such as offering financial compensation or presenting official apologies to the harmed group. We argue that dealing with the past in terms of money or apologies may be appraised differently as a function of ingroup identification. For low identifiers, apologizing may be a good means of dealing with the negative past, and this may alleviate feelings of guilt. For people high in identification, on the other hand, it may be troubling to hear people from their own group confessing the wrongs of the ingroup, and rather than alleviating guilt, it may be disturbing and thus result in relatively high levels of guilt. Thus, it is hypothesized that when an ingroup expresses an apology to the 
victimized group for the ingroup's behavior in the past, ingroup identification will be positively related to group-based guilt.

People high in ingroup identification are expected to be more in favor of dealing with the situation in a manner that does not involve a group-humiliating confession of ingroup wrongs. Instead, they may be more in favor of dealing with the situation in financial ways, such as financial compensation for the victimized group. Offering money to a victimized group does not directly involve an open confession of wrongdoing on the part of the ingroup. Offering money represents an attitude of generally accepting the perpetrator/victim relationship, while potentially solving it in a relatively easy way ('buying a clean conscience'). It can be compared with giving money to charity organizations in order to deal with feelings of guilt that may arise when seeing pictures of a young child dying of hunger in a Third World country. Thus, we argue that when members of an ingroup have offered money to a victimized outgroup to compensate for the harm done by the ingroup in the past, this is likely to alleviate feelings of group-based guilt for people who are highly identified with their group. People who are less identified with their group may still feel uncomfortable about dealing with this situation in purely financial terms. As in Study 1, we measure the extent to which people favor offering financial compensation to the harmed group. We expect to find a negative relation between recommendations for financial compensation and identification when people receive no information about the way in which the ingroup has dealt with the issue in the past (i.e. the control condition). However, we expect to observe a less negative or even positive relation between recommendations for financial compensation and identification when people are informed that their group has apologized in the past for their group's past behavior, because under these circumstances, it is more difficult for high identifiers to deny the responsibility to repair the harm done by their group.

\section{Method}

Participants Altogether, 437 students at a large Dutch university participated in this study. About $70 \%$ of these students were female. The mean age of the sample was 21 years. Students received course credit for participation, and were fully debriefed afterwards.

Design and procedure The design comprised one between-subjects factor: past ingroup behavior in terms of reparations (not specified, apologized, gave money). Participants were first requested to indicate their level of national identification with being Dutch, using the same measure as in Study 1. Again, the eight items formed a highly reliable scale (alpha $=.91)$. Identification was included as a continuous independent variable.

All participants received a historical account of the Dutch colonization of Indonesia, similar to the unfavorable ingroup information presented in Study 1. Immediately thereafter, past ingroup behavior in terms of reparations to the victimized outgroup was manipulated. The manipulation involved information about the way in which the Dutch government has dealt with the legacy of the Dutch colonization of Indonesia. In the not specified condition, the behavior of the Dutch government toward Indonesia after the colonial period was not specified (i.e. control condition). In the apology condition, it was stated that the Dutch government and the present Dutch monarch, Queen Beatrix, have repeatedly apologized to Indonesia on behalf of the Dutch people. This manipulation was reinforced by including a picture of Queen Beatrix with her hand above her chest (as a sort of 'mea culpa' gesture). Finally, in the money condition, people were told that the Dutch government and Queen Beatrix had repeatedly offered money to Indonesia as a financial compensation for their maltreatment.

Dependent measures In order to assess whether participants had perceived the manipulation as intended, they were asked to indicate how the Dutch government had behaved after the colonial period according to the information presented. They could choose 
between three options, with one option being the correct one. As a check on the overall negative tone of the message, participants were asked to indicate how the Dutch had behaved in Indonesia during the colonization, according to the information presented, on a scale ranging from 1 (extremely negative) to 7 (extremely positive).

The main dependent measure of groupbased guilt followed. The same three items as in Study 1 were presented $($ alpha $=.82)$, answered on 7-point scales ranging from 1 (strongly disagree) to 7 (strongly agree). Participants were then requested to indicate the recommendation for financial compensation by their government using the same item as in Study 1 ('I think the Dutch government should make more money available to Indonesia because of the things we have done there in the past'), answered on a scale ranging from 1 (strongly disagree) to 7 (strongly agree).

\section{Results}

All analyses of variance included one betweensubjects factor, past ingroup behavior (not specified, apology, or money) and one continuous independent variable national identification.
Manipulation check Ninety-nine percent of participants indicated the correct past behavior of the Dutch government toward Indonesia after the colonization. Preliminary analysis revealed no differences with or without the remaining $1 \%$, so all participants were retained in the main analyses. On a second check, participants indicated that they perceived the information as negative for their group $(M=$ $1.37, S D=0.77)$, deviating significantly from the scale midpoint $4(t(431)=70.74, p<.001)$.

Group-based guilt It was predicted that identification would be positively related to group-based guilt in the apology condition, whereas identification was expected to be negatively related to guilt in the money condition. The predicted interaction effect between past ingroup behavior and the level of ingroup identification was significant $(F(2,430)=3.47$, $p<.04)$. Figure 3 shows the pattern from this interaction. As predicted, in the apology condition, identification was positively related to group-based guilt $(\beta=.23, t(1,142)=2.87, p<$ $.005)$. In the money condition, identification was slightly negatively related to guilt, although this relation did not differ significantly from

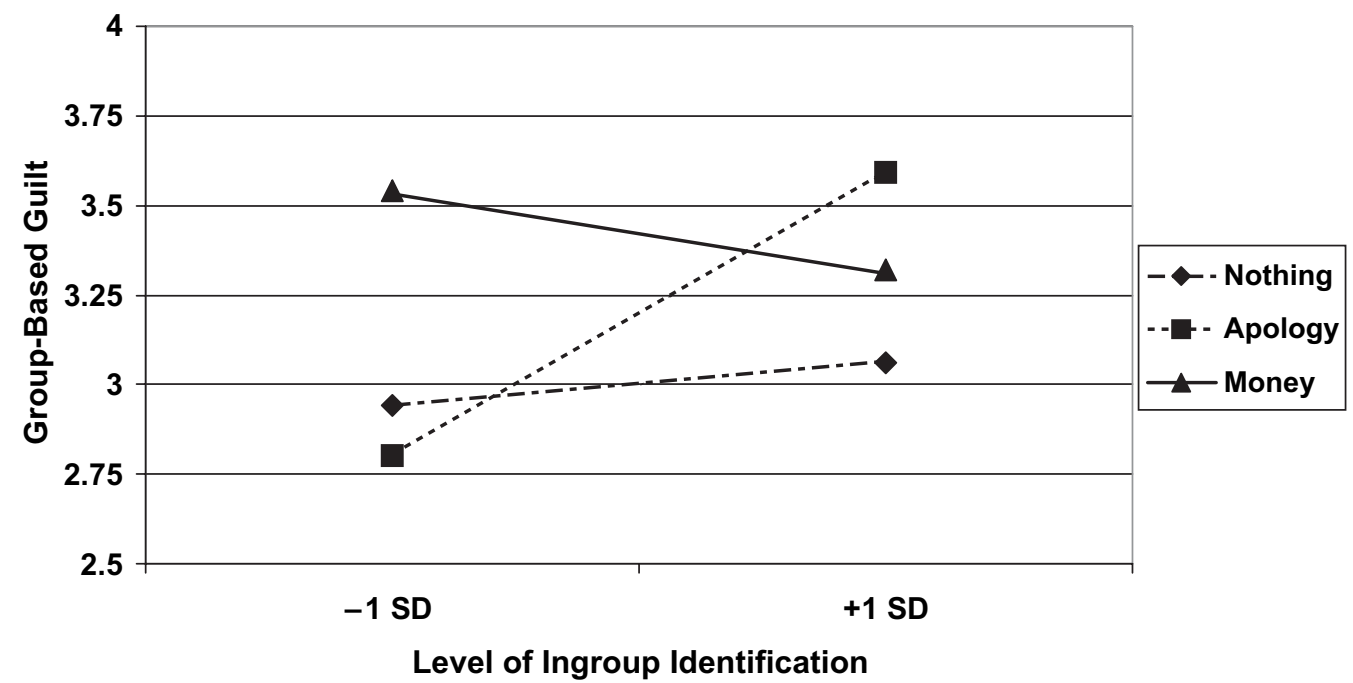

Figure 3. Group-based guilt as a function of past reparation (nothing, apology, and money) and ingroup identification (-1 SD, +1 SD) (Study 2). 
zero $(\beta=-.07, t(1,140)=0.79, p=.43)$. In the condition in which no past reparations were mentioned, there was no significant relation between identification and guilt $(\beta=.04, t(1$, $148)=0.49, p=.62)$. Specific contrast analyses using dummy coding within the regression procedure shows that the slope in the money condition did not differ from the slope in the control condition $(\beta=-.06, t(1,430)=-0.94$, $p=.35$, that the slope in the apology condition differed marginally from the slope in the control condition $(\beta=.11, t(1,430)=1.80, p<$ $.075)$, and that the slopes in the apology and money condition did differ significantly from each other $(\beta=-.18, t(1,430)=-2.60, p<.01)$.

Financial compensation We predicted that identification would be negatively related to recommendations for financial reparations when no information was presented about the ingroup's past behavior in terms of reparation, but that this relation between compensation and identification should be less negative or even positive when the ingroup was said to have offered apologies or given money as a means of past reparation. There was a trend of past ingroup behavior $(F(2,426)=2.91, p<$ $.06)$, a main effect of ingroup identification $(F(1,426)=12.88, p<.001)$, and a significant interaction between these two variables $(F(2$, $426)=3.16, p<.04$ ) (see Figure 4 ). As predicted, the relation between compensation and ingroup identification was negative in the control condition $(\beta=-.32, t(1,147)=4.11, p$ $<.001)$, replicating the finding of Study 1 . However, when the ingroup was said to have apologized $(\beta=-.05, t(1,141)=-0.58, p=.57)$ or already financially compensated the harmed group $(\beta=-.14, t(1,138)=-1.26, p=$ $.11)$, the relation between compensation and ingroup identification became less negative. Specific contrast analyses using dummy coding within the regression procedure shows that the slope in the apology condition differs from the slope in the control condition $(\beta=.15, t(1$, $426)=2.42, p<.02)$, and that the slope in the money condition differed marginally from the slope in the control condition $(\beta=-.11, t(1$, $426)=1.66, p<.10)$. The slopes in the apology and money condition did not differ significantly from each other $(\beta=-.05, t(1,426)=$ $-0.78, p=.43)$.

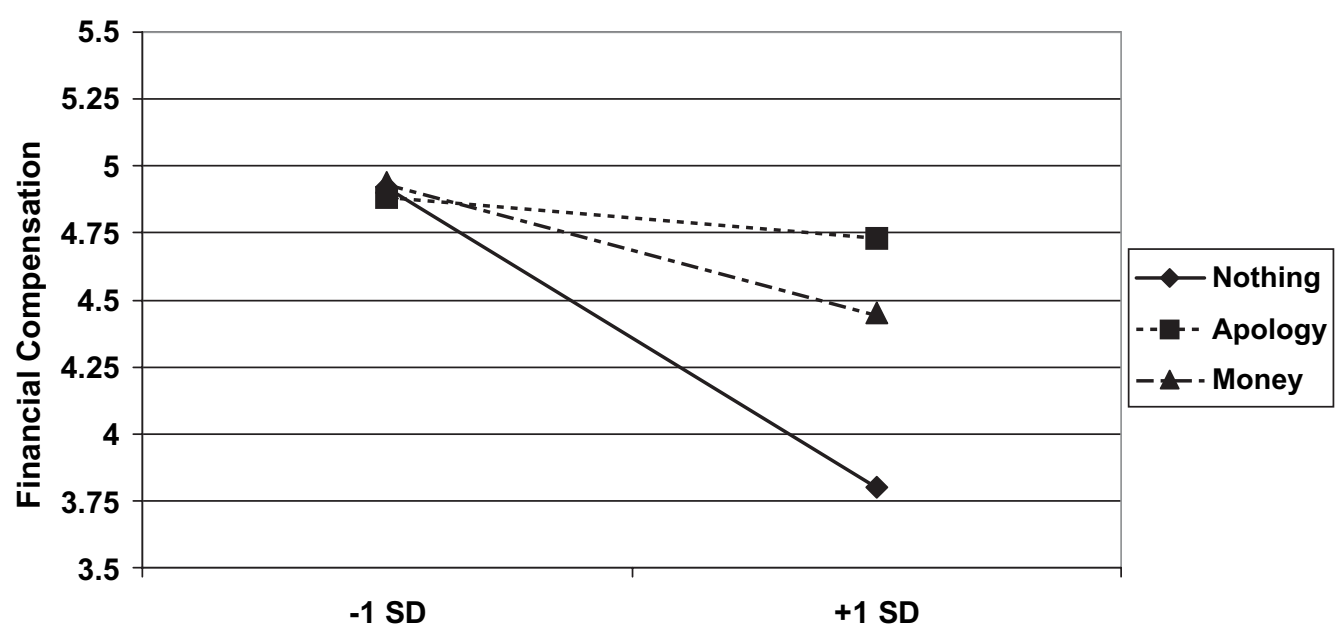

Level of Ingroup Identification

Figure 4. Recommendation for financial reparations as a function of past reparation (nothing, apology, and money) and ingroup identification ( $-1 \mathrm{SD},+1 \mathrm{SD})$ (Study 2). 


\section{Discussion}

This experiment examined the combined effects of past reparation behavior by the ingroup toward a victimized group and ingroup identification on feelings of group-based guilt. Identification was positively related to groupbased guilt when people were told that their ingroup had expressed apologies for their negative behavior toward a victimized outgroup. When people thought their group had given money in the past, there was a nonsignificant trend for people higher in ingroup identification to experience less group-based guilt. Identification was negatively related to recommendations for financial compensation when people were not informed about their group's past reparation behavior, but the relation became less negative when people were under the impression that their group had apologized to the victimized outgroup or had financially compensated the victimized outgroup.

These results have a number of implications. First, they show that level of identification is an important predictor of the way in which people deal with the legacy of their group's past behavior. Identification in combination with an important consequence of guilt, namely reparation behavior, significantly influenced people's present-day feelings of group-based guilt. Specifically, when people do not have a strong attachment to their group, they search for a way to deal with their group's past in a meaningful and psychological manner. They experience relatively high levels of guilt when told that their ingroup has so far only dealt with the past in financial terms, and less guilt when their group has dealt with its past by offering apologies. We argue that offering an apology is costly for the ingroup's image and is therefore more likely to be favored by people who have not invested a great deal in their group membership (Tajfel \& Turner, 1986).

People for whom their group membership is relatively important are more likely to experience group-based guilt when told that their group has acknowledged their mistakes by offering official apologies on a number of occasions. The very fact that it is the ingroup that has accepted responsibility for the past by apologizing for it results in especially high levels of group-based guilt. However, when the harmed outgroup has been compensated financially, high identifiers tended to experience less guilt. It seems that they are more likely than low identifiers to feel their group's legacy can be dealt with in purely financial terms, possibly in an effort to 'buy' a clean conscience.

Looking at the recommendations for financial compensation, it is interesting to observe that high identifiers are only as willing as low identifiers to compensate when their group has acknowledged in some way their mistakes in the past, either by offering apologies or by presenting financial reparation. When the ingroup has not acknowledged their mistakes, identification was negatively related to recommendations for financial compensation, a replication of the finding of Study 1.

\section{General discussion}

The present studies focused on the feelings of group-based guilt that can be experienced as a function of antecedents (Study 1) and consequences of guilt (Study 2), both in combination with ingroup identification. In the first study, we examined the role of an important antecedent of guilt, namely how group membership of the source of the negative information about one's group may have a differential effect on groupbased guilt acceptance, depending on the level of ingroup identification. In the second study, we focused on the consequences of groupbased guilt by investigating the reactions of group members to past ingroup behavior after learning about how the ingroup has dealt with their history in terms of reparation to the harmed group. In both studies, we investigated the reactions of people who differ in their involvement with their national group.

The overall picture that emerges from these studies is that people differ in the way in which they deal with the legacy of their ingroup's past. Specifically, when attachment to the group increases, people are more likely to question the credibility of the source of the information when it comes from an outgroup (Study 1), and 
they are not particularly willing to compensate the harmed group (Study 1 and 2). However, if the ingroup has acknowledged their past behavior by making reparations, high identifiers are as likely as low identifiers to recommend financial compensation to the harmed outgroup (Study 2). In contrast, when people are weakly identified to their group, they are likely to accept the negative message about their group's past, even when it's coming from an outgroup source (Study 1). Those lower in identification are likely to cope with their group's past by feeling relieved (as indicated by showing low levels of group-based guilt) when their group has offered apologies to the harmed outgroup (Study 2). Finally, low identified group members are in favor of financial compensation in the present (Study 1), irrespective of past reparation by their group (Study 2). We believe that these reactions depending on the level of ingroup identification point to a fundamental difference between people in terms of their willingness to accept negative aspects of one's group membership (Doosje et al., 1998). People who are highly identified with their group are less likely to integrate negative aspects of their group membership into their identity than weakly identified group members.

What can we say about the examples of public expressions of wrong-doings, guilt and/or apologies described in the opening? Based on our research, we assume that people who live today may, to some extent, experience emotional reactions such as collective guilt because of their association with the perpetrators in terms of shared group membership with their ancestors. It is also clear from our studies that not everyone is likely to experience these emotions to the same extent. National and/or ethnic identification are important variables for understanding these emotions and accompanying action tendencies. People whose national identity is not a central aspect of the self may be relatively willing to accept possible negative aspects of their nation's history. Consequently, they are more likely to express feelings of guilt (e.g. in South Africa) and offer apologies (e.g. in Belgium) for their group's past behavior. In contrast, for people who place a high value on their national identity, unwillingness to accept negative aspects of their nation's past is more likely to occur. These people are not likely to express their group's wrong doing and guilt, or to offer their apologies. In addition, an official apology by national authorities may alleviate feelings of guilt for members who do not have a strong attachment to their group, but may give rise to strong feelings of guilt among members with a high level of national identification, because for them it may be more disturbing to be reminded about their group's negative past actions.

In these studies, we focused on emotional reactions of the Dutch when they are reminded of their past colonization of Indonesia. Obviously, there are many other countries that have colonized other countries (e.g. Belgium, Britain, France, Germany, Portugal, and Spain), and we argue that in these cases similar emotional processes may operate. In addition, we assume that in general the same psychological processes are working in most contexts in which negative aspects of a country's history are made salient. Thus, we expect to find similar patterns of behavior when looking at nations that have mistreated indigenous people (e.g. the USA, Canada, Australia), nations that were involved in slavery (e.g. Ivory Coast, The Netherlands), and nations that have been involved in genocide (e.g. Germany, Rwanda). At the same time, we realize the contextspecificity and cultural variation that may occur in emotional consequences of immoral actions of one's group. For example, McGarty and Bliuc (in 2004) have argued that national identification may not be the best predictor of guilt in White Australians for their treatment of indigenous people, and that it may be more fruitful to explore identification with specific subgroups within Australia to understand differences in feelings of guilt in that context.

It is clear from our studies that ingroup identification (more specifically, national identification) plays an important role in understanding intergroup emotional experience. Ingroup identification can hinder expressions of guilt in perpetrator groups, 
which could potentially result in victimized groups being less willing to forgive the past. In our view, group identification is a pervasive tool for perceiving and interpreting the world (Haslam, Turner, Oakes, Reynolds, \& Doosje, 2002; Spears, Doosje, \& Ellemers, 1997). When ingroup identification is strong, it may be difficult to accept a negative perspective on the ingroup's past. This makes people more willing to question any criticism of their ingroup in terms of its past harmful actions toward an outgroup. Nonetheless, given the correlational nature of our studies in terms of national identification, it is not possible to draw causal conclusions about its role as an antecedent of collective guilt. It may well be the case that the relation between identification and guilt is a function of a third variable. However, the fact that we have observed interactive effects of identification and other contextual variables makes this possibility less likely.

Our studies have shown the importance of national identification, but mainly in interaction with the source of information (Study 1) and the type of past reparation (Study 2). We have shown how people's responses to their group's past behavior is by no means fixed, but is dependent on the source of information, with the ingroup being more persuasive than an outgroup, especially when ingroup identification is relatively high. In addition, past reparation efforts have different psychological consequences as a function of ingroup identification. Specifically, past apologies are perceived as troubling for people who place a high value on their national identity, while it may provide relief for people for whose national identity is less central. Taken together, our studies have shown the relevance of focusing on contextual antecedents and consequences of guilt in combination with national identification for understanding differences in collective guilt and associated action tendencies.

\section{Acknowledgments}

This research was funded by a Visiting Professorship grant from NWO (the Dutch Organization for Scientific Research) to Nyla R. Branscombe. We thank Sven Zebel for comments on an earlier draft of this paper.

\section{References}

Augoustinos, M., \& LeCouteur, A. (2004). On whether to apologize to indigenous Australians: The denial of white guilt. In N. R. Branscombe \& B. Doosje (Eds.), Collective guilt: International perspectives (pp. 236-261). New York: Cambridge University Press.

Barkan, E. (2000). The guilt of nations: Restitution and negotiating historical injustices. New York: Norton.

Branscombe, N. R. (1998). Thinking about one's gender group's privileges and disadvantages: Consequences for well-being in women and men. British Journal of Social Psychology, 37, 167-184.

Branscombe, N. R., Doosje, B., \& McGarty, C. (2002). Antecedents and consequences of group-based guilt. In D. M. Mackie \& E. R. Smith (Eds.), From prejudice to intergroup emotions: Differentiated reactions to social groups (pp. 49-66). Philadelphia: Psychology Press.

Branscombe, N. R., Ellemers, N., Spears, R., \& Doosje, B. (1999). The context and content of social identity threat. In N. Ellemers, R. Spears, \& B. Doosje (Eds.), Social identity: Context, commitment, content (pp. 35-58). Oxford, UK: Blackwell.

Branscombe, N. R., \& Wann, D. L. (1991). The positive social and self concept consequences of sport team identification. Journal of Sport and Social Issues, 15, 115-127.

Branscombe, N. R., \& Wann, D. L. (1994). Collective self-esteem consequences of outgroup derogation when a valued social identity is on trial. European Journal of Social Psychology, 24, 641-657.

Doosje, B., \& Branscombe, N. R. (2003). Attributions for the negative historical actions of a group. European Journal of Social Psychology, 33, 235-248.

Doosje, B., Branscombe, N. R., Spears, R, \& Manstead, A. S. R. (1998). Guilty by association: When one's group has a negative history. Journal of Personality and Social Psychology, 75, 872-886.

Doosje, B., Ellemers, N., \& Spears, R. (1995). Perceived intragroup variability as a function of group status and identification. Journal of Experimental Social Psychology, 31, 410-436. 
Doosje, B., Spears, R., \& Koomen, W. (1995). When bad isn't all bad: The strategic use of sample information in generalization and stereotyping. Journal of Personality and Social Psychology, 69, 642-655.

Haslam, S. A., Turner, J. C., Oakes, P. J., Reynolds, K. J., \& Doosje, B. (2002). From personal pictures in the head to group-based tools in the world: How shared stereotypes allow groups to represent and manage social reality. In C. McGarty, V. Y. Yzerbyt, \& R. Spears (Eds.), Stereotyping and explanation: The formation of meaningful beliefs about social groups (pp. 157-185). Cambridge, UK: Cambridge University Press.

Hornsey, M. J., Oppes, T., \& Svensson, A. (2002). 'It's OK if we say it, but you can't': Responses to intergroup and intragroup criticism. European Journal of Social Psychology, 32, 293-307.

Kunda, Z. (1990). The case for motivated reasoning. Psychological Bulletin, 106, 395-409.

Lorge, I. (1936). Prestige, suggestion, and attitudes. Journal of Social Psychology, 7, 386-402.

Mackie, D. M., Devos, T., \& Smith, E. R. (2000). Intergroup emotions: Explaining offensive action tendencies in an intergroup context. Journal of Personality and Social Psychology, 79, 602-616.

Mackie, D. M., Gastardo-Conaco, M. C., \& Skelly, J. J. (1992). Knowledge of the advocated position and the processing of ingroup and outgroup persuasive messages. Personality and Social Psychology Bulletin, 18, 145-151.

Mackie, D. M., Worth, L. T., \& Asuncion, A. G. (1990). Processing of persuasive ingroup messages. Journal of Personality and Social Psychology, 57, 812-822.

McGarty, C., \& Bliuc, A.-M. (2004). Refining the meaning of the 'collective' in collective guilt: Harm, guilt and apology in Australia. In N. R. Branscombe \& B. Doosje (Eds.), Collective guilt: International perspectives (pp. 112-129). New York: Cambridge University Press.

Minow, M. (1998). Between vengeance and forgiveness: Facing history after genocide and mass atrocities. Boston: Beacon Press.

Montada, L., \& Schneider, A. (1989). Justice and emotional reactions to the disadvantaged. Social Justice Research, 3, 313-344.

Spears, R., Doosje, B., \& Ellemers, N. (1997). Self-stereotyping in the face of threats to group status and distinctiveness: The role of group identification. Personality and Social Psychology Bulletin, 23, 538-553.
Stangor, C., \& Ford, T. E. (1992). Accuracy and expectancy-confirming processing orientations and the development of stereotypes and prejudice. European Review of Social Psychology, 3, 57-89.

Swim, J. K., \& Miller, D. L. (1999). White guilt: Its antecedents and consequences for attitudes toward affirmative action. Personality and Social Psychology Bulletin, 25, 500-514.

Tajfel, H., \& Turner, J. C. (1986) The social identity theory of intergroup conflict. In S. Worchel \& W. G. Austin (Eds.), Psychology of intergroup relations (pp. 7-24). Chicago: Nelson-Hall.

Turner, J. C., Hogg, M. A., Oakes, P. J., Reicher, S. D., \& Wetherell, M. S. (1987). Rediscovering the social group: A self-categorization theory. Oxford, UK: Basil Blackwell.

Wetherell, M. (1987). Social identity and group polarization. In J. C. Turner, M. A. Hogg, P. J. Oakes, S. D. Reicher, \& M. S. Wetherell (Eds.), Rediscovering the social group: A self-categorization theory (pp. 142-170). Oxford, UK: Basil Blackwell.

Paper received 18 December 2003; revised version accepted 25 May 2005.

\section{Biographical notes}

Bertjan doosje, Social Psychology Program, University of Amsterdam, does research on emotions in intergroup relations, psychological consequences of terrorism, and on partner preferences.

NYLA R. BRANScombe, Department of Psychology, University of Kansas, does research on intergroup relations and on counterfactual thinking and attribution.

RUSSell SPEARs, School of Psychology, Cardiff University; Social Psychology Program, University of Amsterdam, works on social identity, intergroup differentiation and discrimination; computer-mediated communication; intergroup emotions; and automatic behavior.

Antony S. R. MAnstead, School of Psychology, Cardiff University, does reseach on social and cognitive aspects of emotion; attitudes and affect; and identity and social context. 